
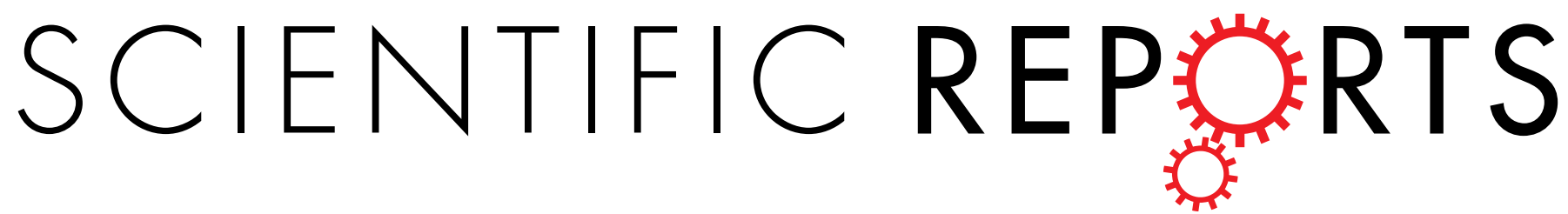

\title{
OPEN Water photolysis effect on the long-term stability of a fiber optic hydrogen sensor with $\mathrm{Pt} / \mathrm{WO}_{3}$
}

Received: 24 June 2016

Accepted: 18 November 2016

Published: 14 December 2016
Xuexiang Zhong ${ }^{1}$, Minghong Yang ${ }^{1,2}{ }^{2}$ Chujia Huang ${ }^{1}$, Gaopeng Wang ${ }^{1}$, Jixiang Dai ${ }^{1}$ \& Wei Bai ${ }^{1}$

One of the technological challenges for hydrogen sensors is long-term stability and reliability. In this article, the UV-light irradiation was introduced into the hydrogen sensing process based on water photolysis effect of $\mathrm{Pt} / \mathrm{WO}_{3}$. Ascribing to that, fiber optic hydrogen sensor with $\mathrm{Pt} / \mathrm{WO}_{3}$ nanosheets as the sensing element was demonstrated with significantly improved performance of stability. Under UV irradiation, the hydrogen sensor exhibits higher sensitivity and resolution together with a smaller error range than that without UV irradiation. The enhanced performance could be attributed to the effective decomposition of water produced in the hydrogen sensing process due to the water photolysis effect of $\mathrm{Pt} / \mathrm{WO}_{3}$. The influence of the water on stability was evaluated using experimental results, and the UV irradiation to remove water was analysed by theoretical and FT-IR spectra. This work provides new strategy of UV-light irradiation to promote the long-term stability of hydrogen sensor using $\mathrm{Pt} / \mathrm{WO}_{3}$ as the sensing element.

With the increasing depletion of coal, oil and other fossil fuels, the development and utilization of new energy has become more important. As is well known, hydrogen is a clean and renewable energy that can be obtained from a wide variety of sources. Due to its status as the smallest molecule, hydrogen can easy leak in the processes of production, transportation, storage and utilization, and due to its flammability, it may explode strongly when its concentration is in a certain value (4-75\%). For this reason, it is extremely important to explore the hydrogen sensors with reliable performance. Compared with conventional hydrogen sensors based on electrical characteristics, the fiber optic hydrogen sensor features excellent characteristics, including intrinsic safety, anti-electromagnetic interference and miniature design. Presently, there are many types of fiber optic hydrogen sensors, such as the interferometric sensor ${ }^{1,2}$, micro-mirror sensor ${ }^{3-5}$, evanescent sensor ${ }^{6-10}$ and fiber Bragg grating (FBG) sensor ${ }^{11-16}$. The FBG hydrogen sensor is especially suitable for distributed measurement and temperature compensation due to its wavelength multiplexing capability. Since the FBG hydrogen sensor is based on wavelength modulation, it can eliminate the influence of light power fluctuations and radically improve the anti-interference ability and stability (stable sensitivity during service period) of the sensor.

Tungsten trioxide $\left(\mathrm{WO}_{3}\right)$ has drawn great research interest due to its special characteristics, including its capabilities of photocatalysis, and electrocatalysis, gasochromic and field-emission properties ${ }^{17-20}$. $\mathrm{WO}_{3}$ is an excellent metal oxide material for hydrogen gas sensing because of its chemical stability and gasochromic properties ${ }^{20,21}$. However, pure $\mathrm{WO}_{3}$ suffers from low sensitivity and a lack of selectivity. Doping with a noble metal, such as Au, $\mathrm{Pt}$ or Pd, is an effective means to enhance the detection of specific gases, as these metal catalysts increase the rate of interaction differently for different gases ${ }^{4,5,10,12,22}$. Among these metal catalysts, $\mathrm{Pt}$ is the most effective catalyst for sensing $\mathrm{H}_{2}$ and effectively increases the response and selectivity towards $\mathrm{H}_{2}$. Due to its fast response and high sensitivity, hydrogen sensors based on $\mathrm{WO}_{3}$ doped with $\mathrm{Pt}\left(\mathrm{Pt} / \mathrm{WO}_{3}\right)$ are of intense interests and have been investigated extensively ${ }^{12,15,16,21,23}$. However, like most hydrogen sensors, degradation is still a severe problem for its application. Therefore, factors affecting the stability of the hydrogen sensor have also been widely investigated, such as water content ${ }^{24-26}$, catalyst poisoning ${ }^{23}$, and phase transition ${ }^{27}$. Among these factors, water content is regarded as an important factor in the long-term stability since water may cover the active Pt surface, resulting in catalyst poisoning and poor stability of the sensor ${ }^{25,28}$. Water can also decrease the sensitivity of the FBG sensors

${ }^{1}$ National Engineering Laboratory for Fiber Optic Sensing Technologies, Wuhan University of Technology, Wuhan, 430070, China. ${ }^{2}$ Key Laboratory of Fiber Optic Sensing Technology and Information Processing, Ministry of Education, China. Correspondence and requests for materials should be addressed to M.Y. (email: minghong.yang@ whut.edu.cn) or C.H. (email: huangchuj@whut.edu.cn) 

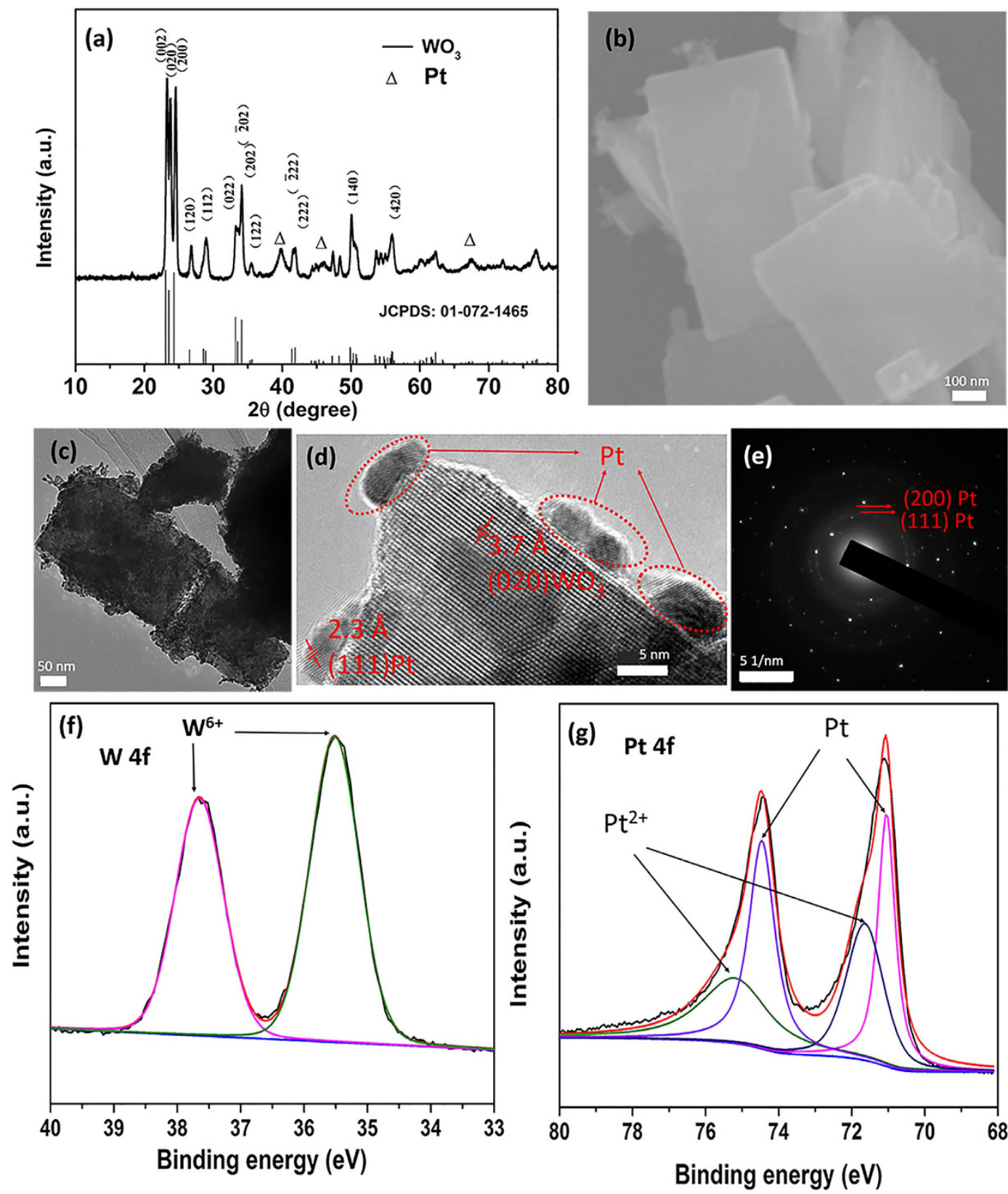

Figure 1. (a) XRD pattern; (b) FE-SEM image; (c) TEM image; (d) HRTEM image; (e) SADE pattern; (f,g) XPS spectra of $\mathrm{Pt} / \mathrm{WO}_{3}$.

which is based on temperature sensing, because water can absorb the heat that is generated by the exothermic reaction between $\mathrm{Pt} / \mathrm{WO}_{3}$ and $\mathrm{H}_{2}{ }^{16}$.

To improve the long-term stability and sensitivity of the fiber optic FBG hydrogen sensors, in this article, an UV-light irradiation strategy was introduced into the hydrogen sensing process based on the water photolysis effect of $\mathrm{Pt} / \mathrm{WO}_{3}{ }^{29-32}$. To the best of our knowledge, while hydrogen sensors based on $\mathrm{WO}_{3}$ gasochromism have been developed and fabricated ${ }^{12,15,16,21,23}$, there have rarely been theoretical or experimental investigations of hydrogen sensors based on the both gasochromic and water photolysis properties of $\mathrm{Pt} / \mathrm{WO}_{3}$. Through continual and systematic experimental tests over 3 months, the hydrogen sensor under UV irradiation exhibits significantly improved long-term stability, and the removal of water under UV irradiation was investigated and demonstrated through FT-IR measurement. The hydrogen sensing principle based on the gasochromism and water photolysis of $\mathrm{Pt} / \mathrm{WO}_{3}$ is discussed.

\section{Results and Discussion}

$\mathrm{Pt} / \mathrm{WO}_{3}$ nanosheets were synthesized by a hydrothermal method followed by annealing. Figure 1 (a) shows the XRD pattern of the $\mathrm{Pt} / \mathrm{WO}_{3}$ nanosheets. The diffraction peaks agree with the monoclinic phase of $\mathrm{WO}_{3}$ with lattice parameters of $\mathrm{a}=7.3 \AA, \mathrm{b}=7.53 \AA$ and $\mathrm{c}=7.68 \AA$ (JCPDS No. 01-072-1465). In addition, there are three 
diffraction peaks at $2 \theta=39.82^{\circ}, 46.31^{\circ}$ and $67.50^{\circ}$, corresponding to the (111), (200) and (220) planes of the cubic phase of Pt (JCPDS No. 00-004-0802), respectively. The morphologies of $\mathrm{Pt} / \mathrm{WO}_{3}$ are shown in Fig. 1(b), which exhibits that the $\mathrm{WO}_{3}$ was mainly composed of uniform nanosheets of approximately $430 \mathrm{~nm} \times 780 \mathrm{~nm}$, and the thickness is in the range of $50-90 \mathrm{~nm}$. The morphology of the $\mathrm{WO}_{3}$ (Fig. S2), shows no significant change after Pt covering.

To obtain further insights into the morphology and structure of the $\mathrm{Pt} / \mathrm{WO}_{3}$ nanosheets, TEM and HRTEM analysis were performed and the results are shown in Figs 1(c,d) and S2. It is clearly observed that the Pt particles effectively covered on the surface of $\mathrm{WO}_{3}$, and the particles size of the Pt is approximately $5-10 \mathrm{~nm}$, which results in the weak peaks of $\mathrm{Pt}$ shown in the XRD pattern. The HRTEM image of the $\mathrm{Pt} / \mathrm{WO}_{3}$ nanosheets shows the typical $\mathrm{WO}_{3}$ and $\mathrm{Pt}$ lattice fringes. The contact between the $\mathrm{WO}_{3}$ and $\mathrm{Pt}$ called ohmic contact, will facilitate electron transfer from the $\mathrm{Pt}$ to the $\mathrm{WO}_{3}$ during the photoexcitation, resulting in enhanced charge separation and photocatalytic efficiency. The periodic fringe spacings of $\sim 3.7$ and $\sim 2.3 \AA$ agree well with the interplanar spacing of the (020) plane of monoclinic $\mathrm{WO}_{3}$ and the (111) plane of cubic $\mathrm{Pt}$, respectively. The selected-area electron diffraction (SAED) pattern (Fig. 1(e)) reveals the crystalline nature of the $\mathrm{Pt} / \mathrm{WO}_{3}$ nanosheets, as also indicated by their XRD result. To obtain the surface chemical composition and state of the $\mathrm{WO}_{3}$ nanosheets, we performed high-resolution XPS analysis. The XPS spectra of $\mathrm{Pt} / \mathrm{WO}_{3}$ are presented in Fig. 1(f) and (g). In the W4f XPS spectrum, the only pair of peaks located at 35.5 and $37.7 \mathrm{eV}$ corresponds to the $\mathrm{W}_{4 / 2}$ and $\mathrm{W}_{7 / 2} \mathrm{f}_{5 / 2}$ of $\mathrm{W}^{6+}$. In the Pt $4 \mathrm{f}$ levels of the samples, the strong doublet decomposition peaks at 71.1 and $74.5 \mathrm{eV}$ could be assigned to metallic $\mathrm{Pt}$, while the weak doublet decomposition peaks at 71.7 and $75.3 \mathrm{eV}$ were corresponded to $\mathrm{Pt}(\mathrm{II})$ oxide, such as $\mathrm{PtO}^{22,33}$. The peak area of metallic $\mathrm{Pt}$ was much larger than that of the $\mathrm{Pt}(\mathrm{II})$ oxide, which indicated that most of the Pt was in the metallic state ${ }^{34}$.

The sensing probe was placed in a sealed chamber for the hydrogen sensing performance calibration. Hydrogen gas at various concentrations was injected into the sealed chamber, and the shifted FBG wavelengths were recorded. The experimental data were fitted by Equation (7) and the linearity was greater than 0.99 (Fig. S3). Subsequently, the cycling stability of the coatings under two different hydrogen sensing process (with and without UV irradiation) was compared. At room temperature, hydrogen concentration was controlled from low to high by a flowmeter and the characteristics of the sensor probes with and without UV irradiation were tested once every two days. To verify the water effect on the sensing stability, experiments were conducted for 40 cycles. The experimental result of the stability test is shown in Fig. 2. 40 cycles were plotted to determine the stability. From Fig. 2(a) and (b), it can be found that in the case of UV irradiation, the cycle stability is better than that without UV irradiation. The error bars and 95\% confidence band in Fig. 2(c) and (d) represent the range that were obtained for each sensor after forty cycles. As shown in Fig. 2(c) and (d), it can be concluded that the FBG characteristic wavelength shift with (without) UV irradiation reaches $380 \mathrm{pm}(270 \mathrm{pm})$ at hydrogen concentration of $15000 \mathrm{ppm}$, which means the average $\mathrm{H}_{2}$ sensitivity is $0.023 \mathrm{pm} / \mathrm{ppm}(0.018 \mathrm{pm} / \mathrm{ppm})$. Given the resolution of the fiber optic spectrometer is $1 \mathrm{pm}$, the equivalent $\mathrm{H}_{2}$ concentration resolution of the sensor is calculated to be $43.5 \mathrm{ppm}$ ( $56 \mathrm{ppm})$. And the greatest discrepancy of the sensor in the relative wavelength shift is $\pm 9.5 \mathrm{pm}$ $( \pm 16 \mathrm{pm})$, which corresponds to $\pm 410.9 \mathrm{ppm}( \pm 888.9 \mathrm{ppm})$ of hydrogen concentration. The minimum error of sensor in the relative wavelength shift is $\pm 0.025 \mathrm{pm}( \pm 0.04 \mathrm{pm})$ which corresponds to $\pm 1.1 \mathrm{ppm}( \pm 2.2 \mathrm{ppm})$ of hydrogen concentration.

From the comparison, it can be concluded that the sensitivity, resolution and stability of the sensing probe with UV irradiation are higher than that those without UV irradiation. These performance properties were attributed to the water decomposition on the surface of the $\mathrm{Pt} / \mathrm{WO}_{3}$ by $\mathrm{UV}$ irradiation. Figure 2(e) displays the response time of the $\mathrm{Pt} / \mathrm{WO}_{3}$ with $\mathrm{UV}$ irradiation under different $\mathrm{H}_{2}$ concentrations. It can be deduced that the response time is approximately 60 s and the recovery time is less than 150 s. The sensor thus presents a good response at room temperature.

The wavelength shifts of the proposed sensor with UV irradiation under different $\mathrm{H}_{2}$ levels in both the ascending and descending condition are shown in Fig. 2(f). It is clear that the two curves are well consistent with each other at various $\mathrm{H}_{2}$ concentrations. However, a small of discrepancy can be seen, and this discrepancy increases with the $\mathrm{H}_{2}$ concentration. The greatest discrepancy was found to be $\pm 5 \mathrm{pm}$, which is reasonable compared with the greatest discrepancy in Fig. 2(d). It should be noted that the time interval between the 35th and 36th hydrogen detection is over one month, which indicates that the sensor shows excellent reversibility and stability.

To explain the water generation process and understand the water decomposition under UV irradiation during the sensing process, a mechanism based on gasochromic and photocatalytic process is proposed and shown in Fig. 3. In a system containing $\mathrm{WO}_{3}$ and $\mathrm{Pt}$, since the work function of $\mathrm{Pt}(5.1 \mathrm{eV})$ is smaller than that of $\mathrm{WO}_{3}(5.7 \mathrm{eV})^{35}$, a deflexion of the energy band of $\mathrm{WO}_{3}$ occurs due to the effect of the ohmic contact (Fig. S4). Consequently, Pt exhibits an excess positive charge, while $\mathrm{WO}_{3}$ accumulates excess $\mathrm{e}^{-}$. When $\mathrm{H}_{2}$ is injected into the chamber, $\mathrm{Pt}$ dissociates the adsorbed $\mathrm{H}_{2}$ molecules into ions and traps the produced electrons $\left(\mathrm{e}^{-}\right)$as an electron pool due to the deflexed energy band. Meanwhile, the $\mathrm{WO}_{3}$ is transformed to unstable compounds $\mathrm{WO}_{3-\mathrm{x}} \cdot \mathrm{xH}_{2} \mathrm{O}$ under the environment of $\mathrm{H}^{+}$.

Subsequently, the color of the $\mathrm{WO}_{3}$ changes to blue. This is the coloration process of $\mathrm{WO}_{3}$ and the reaction can be expressed as the following equation:

$$
\begin{gathered}
\mathrm{H}_{2} \stackrel{P t}{\rightarrow} 2 \mathrm{H}^{+}+2 e^{-} \\
\mathrm{WO}_{3}+2 x \mathrm{H}^{+} \rightarrow \mathrm{WO}_{3-\mathrm{x}} \cdot x \mathrm{H}_{2} \mathrm{O}+2 h^{+}
\end{gathered}
$$

Multi $\mathrm{e}^{-}$trapped by the Pt are then used for the further reduction of oxygen molecules. This leads to the increased generation of $\mathrm{O}_{2}^{-}$and thereby unstable compounds of $\mathrm{WO}_{3-\mathrm{x}} \cdot \mathrm{xH}_{2} \mathrm{O}$ under the environment of $\mathrm{h}^{+}$that 

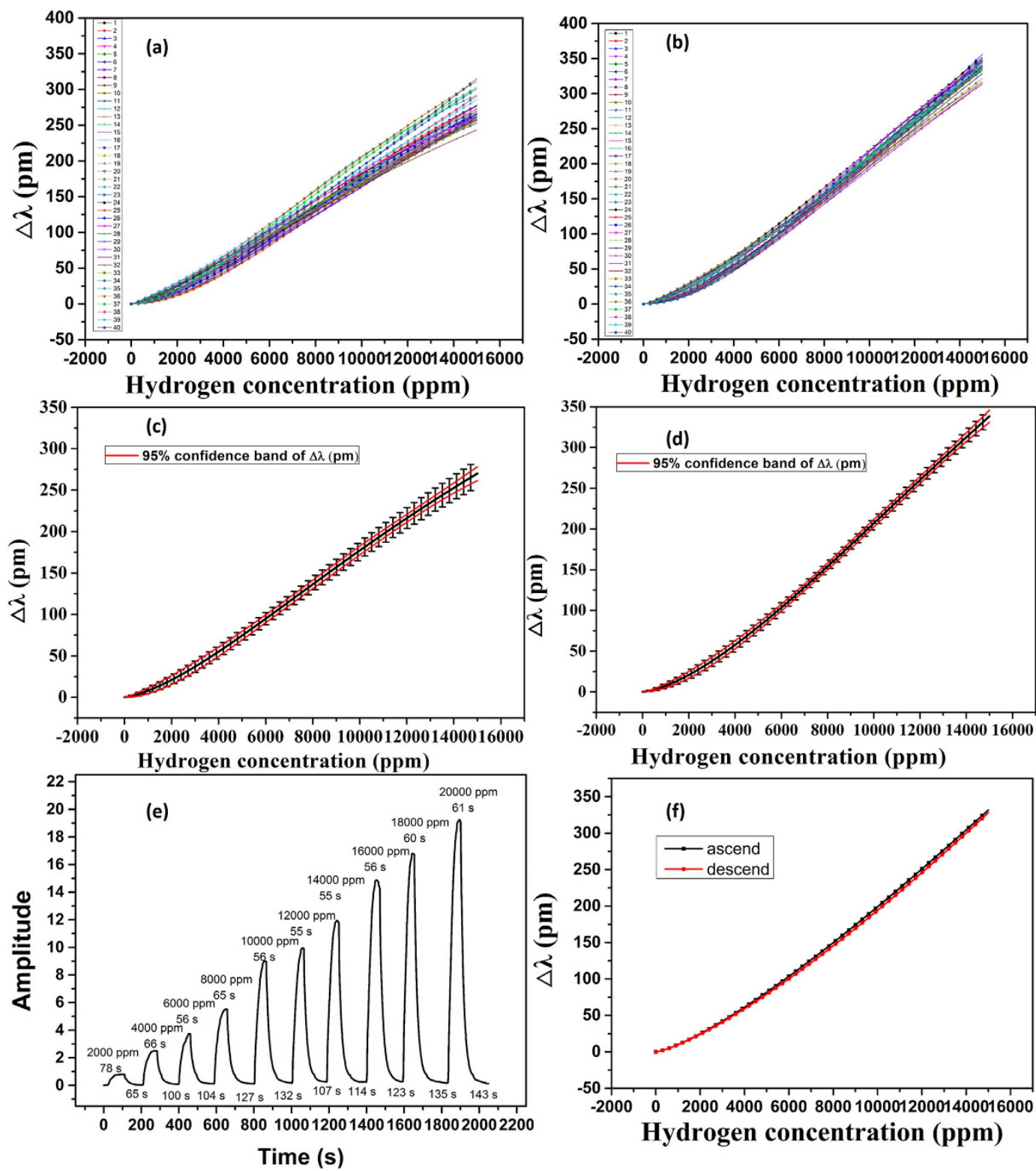

Figure 2. Sensitivity curve for different $\mathrm{H}_{2}$ concentrations (a) without UV irradiation; and (b) with UV irradiation; (c) error analysis of (a); (d) error analysis of (b); (e) time response of sensor in (b); (f) wavelength shifts of $(\mathbf{b})$ under different $\mathrm{H}_{2}$ concentration in both ascending and descending conditions.

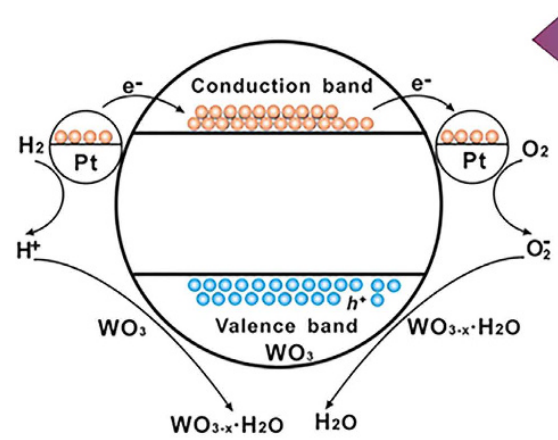

(a)

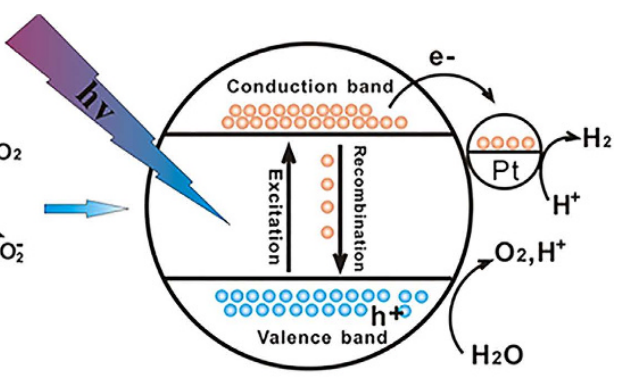

(b)

Figure 3. Schematic illustration of $\mathrm{Pt} / \mathrm{WO}_{3}$ (a) react with $\mathrm{H}_{2}$ and $\mathrm{O}_{2}$; (b) UV water photolysis. 

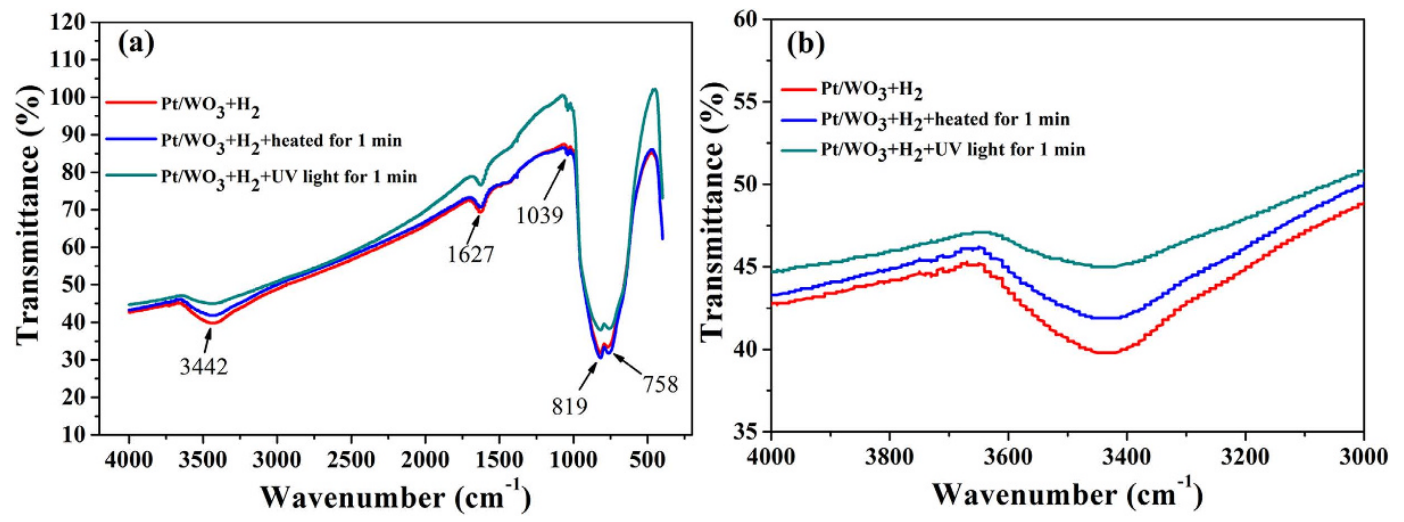

Figure 4. (a) FT-IR spectra of $\mathrm{Pt} / \mathrm{WO}_{3}$; (b) Enlargement of peak at $3442 \mathrm{~cm}^{-1}$.

can be oxidized into $\mathrm{WO}_{3}$. This is the bleaching process of $\mathrm{WO}_{3}$ and the reaction can be expressed as the following equation:

$$
\begin{gathered}
\mathrm{O}_{2}+e^{-} \stackrel{\mathrm{Pt}}{\rightarrow} \mathrm{O}_{2}^{-} \\
\mathrm{WO}_{3-\mathrm{x}} \cdot \mathrm{x} \mathrm{H}_{2} \mathrm{O}+\frac{x}{2} h^{+}+\frac{x}{2} \mathrm{O}_{2}^{-} \rightarrow \mathrm{WO}_{3}+x \mathrm{H}_{2} \mathrm{O}
\end{gathered}
$$

When UV light is irradiated (hv) onto the $\mathrm{Pt} / \mathrm{WO}_{3}$ system, electrons $\left(\mathrm{e}^{-}\right)$are generated in the conduction band $(\mathrm{CB})$ and holes $\left(\mathrm{h}^{+}\right)$are generated in the valence band (VB). These photo-induced holes likely remained in the VB of $\mathrm{WO}_{3}$, whereas electrons are trapped in the $\mathrm{CB}$ of $\mathrm{Pt}$, resulting in an efficient space separation of photo-induced charge carriers. The holes stored in the $\mathrm{VB}$ of the $\mathrm{WO}_{3}$ are used for splitting $\mathrm{H}_{2} \mathrm{O}$ molecule in the air near the surface of the $\mathrm{WO}_{3}$ into $\mathrm{H}^{+}$and $\mathrm{O}_{2}$, and the produced $\mathrm{H}^{+}$is then transferred to the surface of the $\mathrm{Pt}$ and reduced to $\mathrm{H}_{2}$ by absorbing $\mathrm{e}^{-}$. The major steps in this mechanism under UV light irradiation are summarized in the following reactions ${ }^{29,36}$ :

$$
\begin{gathered}
\mathrm{H}_{2} \mathrm{O}+2 h^{+} \stackrel{h \nu}{\rightarrow} 2 \mathrm{H}^{+}+\frac{1}{2} \mathrm{O}_{2} \\
2 \mathrm{H}^{+}+2 \mathrm{e}^{-} \stackrel{\mathrm{Pt}}{\rightarrow} H_{2}
\end{gathered}
$$

To verify the water photolysis effect of the UV irradiation on the decomposition of water, the sample reacted with $\mathrm{H}_{2}$ was characterized by FT-IR after irradiated by UV and heated at $120^{\circ} \mathrm{C}$ for $1 \mathrm{~min}$ respectively. The FT-IR spectra are shown in Fig. 4. The intense broad band observed at $3442 \mathrm{~cm}^{-1}$ and $1627 \mathrm{~cm}^{-1}$ are due to the O-H stretching vibrations and bending vibrations of $\mathrm{H}_{2} \mathrm{O}$, respectively ${ }^{36}$. The peak at $1039 \mathrm{~cm}^{-1}$ corresponds to the $\mathrm{W}-\mathrm{OH}$ bending vibration mode ${ }^{37}$, while the absorption peaks at $819 \mathrm{~cm}^{-1}$, and $758 \mathrm{~cm}^{-1}$ are assigned to the $\mathrm{O}-\mathrm{W}-\mathrm{O}$ bonds of $\mathrm{WO}_{3}{ }^{36}$. It can be observed that the peak intensity of the $3442 \mathrm{~cm}^{-1}$ significantly reduced under UV irradiation for $1 \mathrm{~min}$, while the peak intensity is only weakened slightly after heating at $120^{\circ} \mathrm{C}$ for $1 \mathrm{~min}$, indicating that the strategy of UV irradiation has distinct superiority for the remove of the water. FT-IR results of the samples irradiated with UV light for different time were obtained (Fig. S5). There is a distinct decreasing trend of the peak intensity at $3442 \mathrm{~cm}^{-1}$ as the time increase, indicating the gradual removal of water.

Based on the results and analysis above, the UV-light irradiation is an effective method to eliminate the water produced during the hydrogen sensing process. Ascribing to that, the stability and sensitivity of the hydrogen sensor under UV irradiation are greatly improved.

\section{Conclusions}

In summary, $\mathrm{Pt} / \mathrm{WO}_{3}$ nanosheets have been successfully fabricated and deposited on an FBG for hydrogen detection. Different from previous reports, an UV-light irradiation strategy was introduced into the hydrogen sensing process to eliminate the produced water based on the water photolysis effect of $\mathrm{Pt} / \mathrm{WO}_{3}$. Ascribing to that, the hydrogen sensor under UV irradiation exhibits significantly improved long-term stability through experimental tests over 3 months. The sensor also shows higher sensitivity $(0.023 \mathrm{pm} / \mathrm{ppm})$ and resolution $(43.5 \mathrm{ppm})$ with UV irradiation than that without UV irradiation. Through the FT-IR spectra, the UV irradiation on the decomposition of the water produced in the hydrogen sensing process is confirmed. This study provides a new strategy of $\mathrm{UV}$-light irradiation to promote the long-term stability of a hydrogen sensor with $\mathrm{Pt} / \mathrm{WO}_{3}$ as the sensing element.

\section{Methods}

Synthesis. $\mathrm{WO}_{3} \cdot \mathrm{H}_{2} \mathrm{O}$ nanosheets were synthesized by a hydrothermal method as reported in a previous work ${ }^{38}$. In a typical process, $0.66 \mathrm{~g}$ of sodium tungstate $\left(\mathrm{Na}_{2} \mathrm{WO}_{4} \cdot 2 \mathrm{H}_{2} \mathrm{O}\right)$ and $0.4 \mathrm{~g}$ of citric acid were mixed and dissolved into $40 \mathrm{~mL}$ of distilled water under $10 \mathrm{~min}$ of magnetic stirring to form a transparent solution. Then the aqueous solution was slowly acidified to a $\mathrm{pH}$ range of $1-1.2$ with $10 \mathrm{~mL}$ of $3 \mathrm{~mol} / \mathrm{L} \mathrm{HCl}$. Subsequently, a yellow 


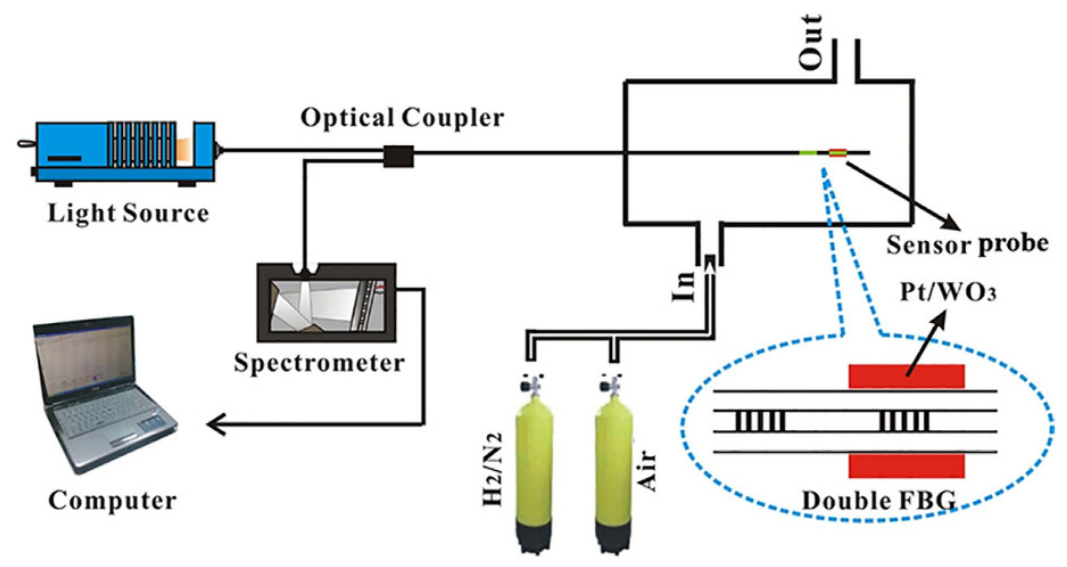

Figure 5. Configuration of FBG hydrogen sensor.

precipitate was obtained, and $0.8 \mathrm{~g}$ oxalic acid was added into solution. After $20 \mathrm{~min}$ of stirring, the solution was transferred into a $50-\mathrm{mL}$ Teflon-lined stainless steel autoclave, that was sealed and heated at $160^{\circ} \mathrm{C}$ for $12 \mathrm{~h}$, and then cooled to room temperature naturally. The obtained precipitates were separated by centrifugation, washed several times with distilled water and absolute ethanol and then dried in air at $60^{\circ} \mathrm{C}$ for $4 \mathrm{~h}$. After that, $1 \mathrm{mmol}$ of the as-synthesized $\mathrm{WO}_{3} \cdot \mathrm{H}_{2} \mathrm{O}$ and $0.2 \mathrm{mmol}$ acetyl acetone platinum $\left(\mathrm{Pt}(\mathrm{acac})_{2}\right)$ were mixed. The mixture was grinded sufficiently and annealed in air at $315^{\circ} \mathrm{C}$ at a heating rate of $10^{\circ} \mathrm{C} / \mathrm{min}$ for $2 \mathrm{~h}$ to obtain $\mathrm{Pt} / \mathrm{WO}_{3}$ nanosheets.

Characterization. The phase of the $\mathrm{Pt} / \mathrm{WO}_{3}$ was investigated by X-ray diffraction (XRD) using a Bruker D8 Advance X-ray diffractometer with $\mathrm{Cu} \mathrm{K} \alpha \mathrm{X}$-ray source. The morphology was characterized by using a Zeiss Ultra Plus field emission scanning electron microscope (FE-SEM). Transmission electron microscopic (TEM), high resolution transmission electron microscopic (HRTEM) images and selected area electron diffraction (SAED) pattern were collected using a JEOL JEM-2100F STEM/EDS microscope. FT-IR spectra were obtained with Thermo Scientific Nicolet 6700 . The oxidation state and relative chemical composition of $\mathrm{Pt} / \mathrm{WO}_{3}$ were evaluated by X-ray photoelectron spectroscopy (XPS) in a Kratos AXIS-ULTRA DLD-600 W.

Fabrication of sensor probe. The sensor device was fabricated by uniformly coating the as-synthesized $\mathrm{Pt} / \mathrm{WO}_{3}$ powder mixed with an appropriate amount of de-ionized water on the FBG fiber, and the FBG fiber was fixed on a glass substrate with a groove so that the $\mathrm{Pt} / \mathrm{WO}_{3}$ coating could be stably immobilized on the section of the FBG grating.

Hydrogen sensing characterization. Figure 5 shows a schematic of the configuration of the FBG hydrogen sensing characterization system. The system consists of a tunable light source, a 3-dB optical fiber coupler, a sensing probe and a customized optical spectrum analyzer with a resolution of $1 \mathrm{pm}$. The sensing probe consists of two FBGs, one employed for temperature compensation, and other FBG coated with $\mathrm{Pt} / \mathrm{WO}_{3}$ detect hydrogen as the sensing probe. The hydrogen sensing performance test was conducted at room temperature with nitrogen as the carrier gas (with an ambient $50 \% \mathrm{RH}$ ). Mixture of nitrogen and hydrogen with variable $\mathrm{H}_{2}$ concentrations were provided by a Beijing Sevenstar Electronics CS200 flowmeter with a resolution of $1 \mathrm{ppm}$. The hydrogen sensing process was divided into two stages: (i) the sensor probe was exposed to a mixture of nitrogen and hydrogen with a variable $\mathrm{H}_{2}$ concentrations and the spectrum of the tested $\mathrm{FBG}$ with $\mathrm{Pt} / \mathrm{WO}_{3}$ was measured and (ii) after that, the sample was exposed to air along with (or without) ultraviolet light $(\lambda=365 \mathrm{~nm})$ irradiation for $1 \mathrm{~min}$ at $8 \mathrm{~W} / \mathrm{cm}^{2}$ using a EXFO LX300 smart LED point light curing equipment to decompose the water that was generated in stage (i). The relationship between the center wavelength of the FBG and the temperature change has been reported in our previous work ${ }^{15}$, and the $\mathrm{FBG}$ theory based on the $\mathrm{Pt} / \mathrm{WO}_{3}$ coatings can be described as:

$$
\Delta \lambda=\frac{a \times b \times x^{n}}{1+b \times x^{n}}
$$

where "a" is related to the hydrogen media sensing material and " $b$ " and " $n$ " are constants of reactions. A detail derivation of Equation (7) was presented in the Supplementary Information.

\section{References}

1. Butler, M. A. Optical fiber hydrogen sensor. Appl. Phys. Lett. 45, 1007-1009 (1984).

2. Farahi, F., Leilabady, P. A., Jones, J. D. C. \& Jackson, D. A. Optical-fibre flammable gas sensor. Journal of Physics E Scientific Instruments 20 (2000)

3. Butler, M. A. Micromirror optical-fiber hydrogen sensor. Sensor. Actuat. B-Chem. 22, 155-163 (1994).

4. Yang, M., Liu, H., Zhang, D. \& Tong, X. Hydrogen sensing performance comparison of Pd layer and $\mathrm{Pd} / \mathrm{WO}_{3}$ composite thin film coated on side-polished single- and multimode fibers. Sensor. Actuat. B-Chem. 149, 161-164 (2010).

5. Luna-Moreno, D., Monzón-Hernández, D., Villatoro, J. \& Badenes, G. Optical fiber hydrogen sensor based on core diameter mismatch and annealed Pd-Au thin films. Sensor. Actuat. B-Chem. 125, 66-71 (2007). 
6. Tabib-Azar, M., Sutapun, B., Petrick, R. \& Kazemi, A. Highly sensitive hydrogen sensors using palladium coated fiber optics with exposed cores and evanescent field interactions. Proc Spie 56, 158-163 (1999).

7. Khijwania, S. K. \& Gupta, B. D. Fiber optic evanescent field absorption sensor: Effect of fiber parameters and geometry of the probe. Optical \& Quantum Electronics 31, 625-636 (1999).

8. Sekimoto, S. et al. A fiber-optic evanescent-wave hydrogen gas sensor using palladium-supported tungsten oxide. Sensor. Actuat. B-Chem. 66, 142-145 (2000).

9. Okazaki, S. et al. Sensing characteristics of an optical fiber sensor for hydrogen leak. Sensor. Actuat. B-Chem. 93, 142-147 (2003).

10. Monzón-Hernández, D., Luna-Moreno, D. \& Martínez-Escobar, D. Fast response fiber optic hydrogen sensor based on palladium and gold nano-layers. Sensor. Actuat. B-Chem. 136, 562-566 (2009).

11. Sutapun, B., Tabib-Azar, M. \& Kazemi, A. Pd-coated elastooptic fiber optic Bragg grating sensors for multiplexed hydrogen sensing. Sensor. Actuat. B-Chem. 60, 27-34 (1999).

12. Dai, J. et al. Performance of fiber Bragg grating hydrogen sensor coated with Pt-loaded $\mathrm{WO}_{3}$ coating. Sensor. Actuat. B-Chem. 190, 657-663 (2014).

13. Tien, C. L. et al. Hydrogen sensor based on side-polished fiber Bragg gratings coated with thin palladium film. Thin Solid Films 516, 5360-5363 (2008).

14. Caucheteur, C., Debliquy, M., Lahem, D. \& Megret, P. Catalytic Fiber Bragg Grating Sensor for Hydrogen Leak Detection in Air. IEEE Photonic. Tech. L. 20, 96-98 (2008).

15. Yang, M., Yang, Z., Dai, J. \& Zhang, D. Fiber optic hydrogen sensors with sol-gel $\mathrm{WO}_{3}$ coatings. Sensor. Actuat. B-Chem. 166-167, 632-636 (2012).

16. Caucheteur, C., Debliquy, M., Lahem, D. \& Megret, P. Hybrid fiber gratings coated with a catalytic sensitive layer for hydrogen sensing in air. Opt. Express 16, 16854-16859 (2008).

17. Li, Y., Bo, Y. \& Golberg, D. Quasi-aligned single-crystalline $\mathrm{W}_{18} \mathrm{O}_{49}$ nanotubes and nanowires. Adv. Mater. 15, 1294-1296 (2003).

18. Jin, J., Yu, J., Guo, D., Cui, C. \& Ho, W. A Hierarchical Z-Scheme CdS- $\mathrm{WO}_{3}$ Photocatalyst with Enhanced $\mathrm{CO}_{2}$ Reduction Activity. Small 11, 5262-5271 (2015).

19. Liao, C. C., Chen, F. R. \& Kai, J. J. $\mathrm{WO}_{3-\mathrm{x}}$ nanowires based electrochromic devices. Sol. Energ. Mat. Sol. C. 90, 1147-1155 (2006).

20. Li, D., Wu, G., Gao, G., Shen, J. \& Huang, F. Ultrafast coloring-bleaching performance of nanoporous $\mathrm{WO}_{3}-\mathrm{SiO}_{2}$ gasochromic films doped with Pd catalyst. Acs Appl. Mater. Inter. 3, 4573-4579 (2011).

21. Ippolito, S. J., Kandasamy, S. \& Kalantar, K. Hydrogen sensing characteristics of $\mathrm{WO}_{3}$ thin film conductometric sensors activated by Pt and Au catalysts. Sensor. Actuat. B-Chem. 108, 154-158 (2005).

22. Kukkola, J. et al. Room temperature hydrogen sensors based on metal decorated $\mathrm{WO}_{3}$ nanowires. Sensor. Actuat. B-Chem. 186, 90-95 (2013).

23. Luo, J. Y. et al. Study of the catalyst poisoning and reactivation of Pt nanoparticles on the surface of $\mathrm{WO}_{3}$ nanowire in gasochromic coloration. Sensor. Actuat. B-Chem. 171-172, 1117-1124 (2012).

24. Shi, J. C. et al. Effects of water on the gasochromc properties of $\mathrm{WO}_{3}$ thin films. Journal of Functional Materials \& Devices 15, 459-465 (2009).

25. Lee, S. H. et al. Gasochromic mechanism in a- $\mathrm{WO}_{3}$ thin films based on Raman spectroscopic studies. J. Appl. Phys. 88, 3076-3078 (2000).

26. Ghosh, A., Prasad, J., Bharadwaj, S., Ali, S. S. \& Chengalur, J. N. The role of water in gasochromic $\mathrm{WO}_{3}$ films. Thin Solid Films 384, 269-275 (2001)

27. Gao, G. et al. Phase transition effect on durability of $\mathrm{WO}_{3}$ hydrogen sensing films: An insight by experiment and first-principle method. Sensor. Actuat. B-Chem. 171-172, 1288-1291 (2012).

28. Jang, J. H., Lee, E. \& Kwon, Y. U. Enhanced electrocatalytic performance for hydrogen oxidation reaction on gold nanoparticles supported on tungsten oxide (VI) modified carbon. Int. J. Hydrogen Energ. 37, 8170-8176 (2012).

29. Liu, X., Wang, F. \& Wang, Q. Nanostructure-based $\mathrm{WO}_{3}$ photoanodes for photoelectrochemical water splitting. Phys. Chem. Chem. Phys. 14, 7894-911 (2012).

30. Kudo, A. \& Miseki, Y. Heterogeneous photocatalyst materials for water splitting. Chem. Soc. Rev. 38, 253-278 (2009).

31. Chen, X., Shen, S., Guo, L. \& Mao, S. S. Semiconductor-based photocatalytic hydrogen generation. Chem. Rev. 110, 6503-6570 (2010).

32. Osterloh, F. E. ChemInform abstract: inorganic materials as catalysts for photochemical splitting of water. Cheminform 39, 35-54 (2008).

33. Hsieh, C. T., Chen, W. Y., Chen, I. L. \& Roy, A. K. Deposition and activity stability of Pt-Co catalysts on carbon nanotube-based electrodes prepared by microwave-assisted synthesis. J. Power Sources 199, 94-102 (2012).

34. Peng, F. et al. The role of $\mathrm{RuO}_{2}$ in the electrocatalytic oxidation of methanol for direct methanol fuel cell. Catal. Commun. 10, 533-537 (2009).

35. Arutanti, O., Nandiyanto, A. B., Ogi, T., Kim, T. O. \& Okuyama, K. Influences of Porous Structurization and Pt Addition on the Improvement of Photocatalytic Performance of $\mathrm{WO}_{3}$ Particles. Acs Appl. Mater. Inter. 7, 3009-3017 (2015).

36. Fujii, A. et al. Preparation of Pt-loaded $\mathrm{WO}_{3}$ with different types of morphology and photocatalytic degradation of methylene blue. Surf. Coat. Tech. 271, 251-258 (2015).

37. Garde, A. S. Humidity sensing properties of $\mathrm{WO}_{3}$ thick film resistor prepared by screen printing technique. J. Alloy. Compd. 617, 367-373 (2014)

38. Zeng, W., Li, Y., Miao, B. \& Pan, K. Hydrothermal synthesis and gas sensing properties of $\mathrm{WO}_{3} \cdot \mathrm{H}_{2} \mathrm{O}$ with different morphologies. Physica E. 56, 183-188 (2014)

\section{Acknowledgements}

This work is financially supported by the National Natural Science Foundation of China, NSFC (Project Number: 61575151, 51402228), the Creative Group Project of Hubei Provincial Natural Science Foundation (Project Number: 2015CFA016) and Project of National Natural Science Foundation of Hubei Provincial Government (Number: 2014CFB260).

\section{Author Contributions}

M.Y. proposed and coordinated the work. X.Z. and C.H. developed the idea, designed the system and prepared the sample. G.W. and W.B. tested the sensing probe. J.D. analyzed the date. All authors discussed the results. X.Z., C.H. and M.Y. drafted the manuscript.

\section{Additional Information}

Supplementary information accompanies this paper at http://www.nature.com/srep

Competing financial interests: The authors declare no competing financial interests. 
How to cite this article: Zhong, X. et al. Water photolysis effect on the long-term stability of a fiber optic hydrogen sensor with $\mathrm{Pt} / \mathrm{WO}_{3}$. Sci. Rep. 6, 39160; doi: 10.1038/srep39160 (2016).

Publisher's note: Springer Nature remains neutral with regard to jurisdictional claims in published maps and institutional affiliations.

(c) (i) This work is licensed under a Creative Commons Attribution 4.0 International License. The images or other third party material in this article are included in the article's Creative Commons license, unless indicated otherwise in the credit line; if the material is not included under the Creative Commons license, users will need to obtain permission from the license holder to reproduce the material. To view a copy of this license, visit http://creativecommons.org/licenses/by/4.0/

(C) The Author(s) 2016 